$$
\begin{aligned}
& \text { 震 } \\
& \text { 满 }
\end{aligned}
$$

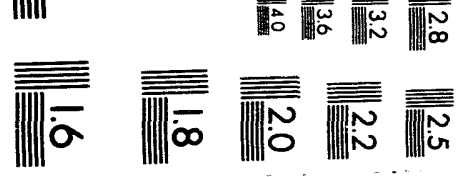



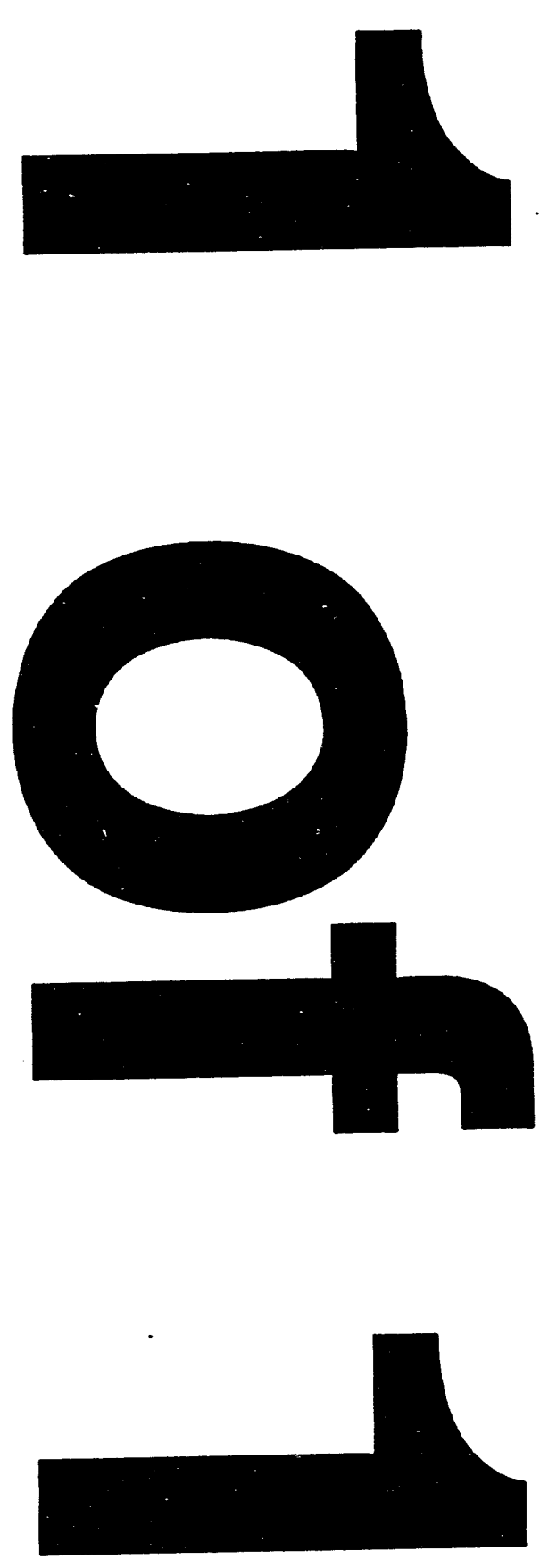


\section{SCIENTIFIC COMPUTATIONS SECTION MONTHLY REPORT SEPTEMBER 1993 (U)}

by

M. R. Buckner

Westinghouse Savannah River Company

Savannah River Site

Aiken, South Carolina 29808

This paper was prepared in connection with work done under the above contract number with the U. S. Department of Energy. By acceptance of this paper, the publisher and/or recipient acknowledges the U. S. Government's right to retain a nonexclusive, royalty-free license in and to any copyright covering this paper, along with the right to reproduce and to authorize others to reproduce all or part of the copyrighted paper. 


\section{DISCLAIMER}

This report was prepared as an account of work sponsored by an agency of the United States Government. Neither the United States Government nor any agency thereof, nor any of their employees, makes any warranty, express or implied, or assumes any legal liability or responsibility for the accuracy, completeness, or usefulness of any information, apparatus, product, or process disclosed, or represents that its use would not infringe privately owned rights. Reference herein to any specific commercial product, process, or service by trade name, trademark, manufacturer, or otherwise does not necessarily constitute or imply its endorsement, recommendation, or favoring by the United States Government or any agency thereof. The views and opinions of authors expressed herein do not necessarily state or reflect those of the United States Government or any agency thereof.

This report has been reproduced directly from the best available copy.

Available to DOE and DOE contractors from the Office of Scientific and Technical Information, P. O. Box 62, Oak Ridge, TN 37831; prices available from (615) $576-8401$.

Available to the public from the National Technical Information Service, U. S. Department of Commerce, 5285 Port Royal Rd., Springfield, VA 22161 
Westinghouse Savannah River Company

Inter-Office Memorandum

November 1, 1993

To: $\quad$ Fred Beranek, 773-A

From: M. R. Buckno, $773-42 A$

5-3149

Scientific Computations Section

Monthly Report

September 1993 


\section{Table of Contents}

Table of Contents

Abstracts .1

Administrative 5

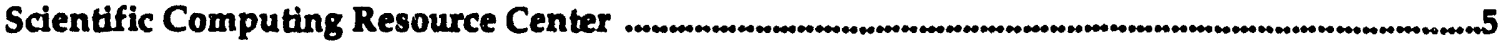

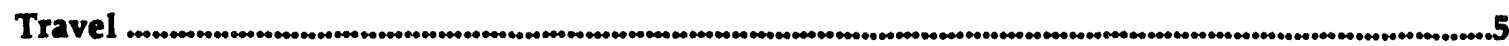

\section{COMPUTATIONAL MODELING}

(J. R. Pelfrey, Manager)

Engineering Modeling 7

Thermal Analysis of Glass Waste Storage Canisters - S. J. Hensel.......................................................7

Deflagration Analysis of DWPF Tanks - S. J. Hensel ....................................................................7

Thermal Evaluation of the 9965, 9966, 9967, and 968 Shipping Packages - J. W. Jerrell, S. J. Hensel.

Structural Analysis of Closure Cap Barriers - A Pre-test Study for the Bentonite Mat

Demonstration Project - C. Gong ..................................................................................................8

High Level Waste Simulation Package - M.V. Gregory .............................................................................9

Training on F-Canyon Ventilation Model - J. E. Aull ...............................................................................9

High Level Waste Model User Interface - J. E. Aull, K. L. Shanahan ..............................................10

SPEEDUP Installation on VAXstation - J. E. Aull, K. L. Shanahan ..................................................10

\section{APPLIED STATISTICS}

(R. C. Tuckfield, Manager)

Environmental Monitoring Section's Data Analysis Program (EMDAP) Delivered - M. D. Wise, R. C. Tuckfield, G. R. Morton, E. W. Jenkins .........................................................................11 Aluminum Nitrate Testing at the Effluent Treatment Facility - M. D. Wise .................................11

\section{APPLIED PHYSICS}

\section{(C. E. Apperson, Manager)}

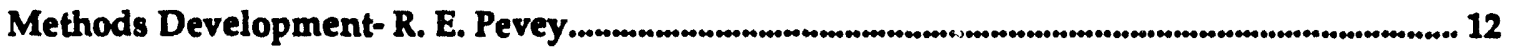

Programmer's Environment and Configuration Control - P. W. Wyatt........................................12

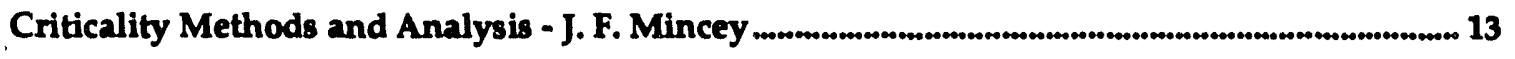

Experimental Benchmark Descriptions - E.F. Trumble, R.L. Frost, J.B. Justice .............................13

DOE Order 5480.24 Compliance - R. L. Reed .......................................................................................14

100 Area Fuel Consolidation Support Activities - R. L. Reed and S. Y. Lee ....................................14

100 Area Support Activities -Mark 42 Criticality - R. L. Reed ..............................................................15

100 Area Support Activities -PVC Enclosures for K-15 Fuel - R. L. Reed .....................................15

Technical Reviews: K Disassembly VTS Cleanup - R. L. Reed .........................................................15

Technical Reviews: TA -93-0003-0001 (Loading of Borated Racks in 321-M with defueling ingots) - R. L. Reed ............................................................................................................................16

Technical Reviews: Improved Storage of Corroding Mark 31A Slugs in L Area - R. L. Reed.

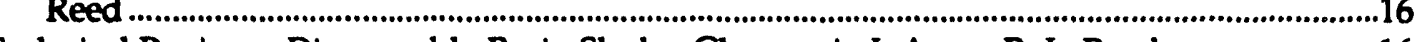

Technical Reviews: Disassembly Basin Sludge Cleanup in L Area - R. L. Reed............................16

USF Waste Handling Facility NIM Studies - J. F. Zino, K. C. Okafor, and R. L. Webb................16

AMPX-77 Certification - K. A. Niemer .................................................................................................17 
Installation and Testing of SCALE4.1 - ORIGENS - J. H. Hightower

\section{EXPERIMENTAL THERMAL HYDRAULICS}

(D. R. Muhlbaier, Manager)

Enhanced Waste-Tank Level Model - M. R. Duignan ................................................................18

FRR Spent Fuel Dry Storage Development - H. N. Guerrero ..........................................................18

Pilot Scale Demonstration of HEME Dissolution Process - Z H. Qureshi....................................19

ITP Filter Replacement Capability - A. C. Smith …….................................................................19

Plasma Technology Users Facility - T. L. Spatz ……......................................................................19

E7 Manual Orientation - T. J. Steeper ....................................................................................19

Crossflow Filter Test - J. L. Steimke ..................................................................................................20

Air Cooling of Glass Canisters - J. L. Steimke .........................................................................................20

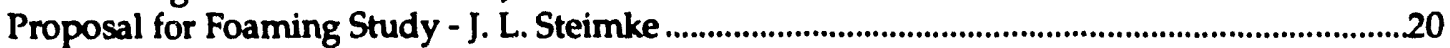

Rectifier Operating Procedure - J. L. Steimke.............................................................................20

Support to Low Level Mixed Waste Vitrification Program - J. C. Whitehouse..............................21

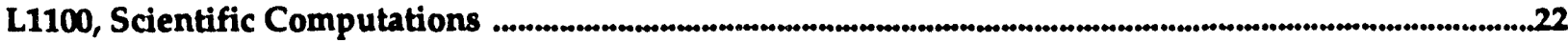

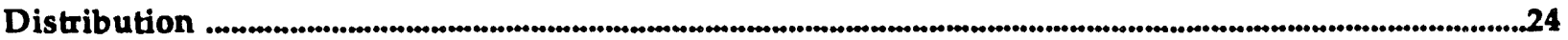




\title{
Abstracts
}

\author{
COMPUTATIONAL MODELING \\ (J. R. Pelfrey, Manager)
}

\section{Engineering Modeling}

Thermal Analysis of Glass Waste Storage Canisters - S. J. Hensel

A preliminary thermal analysis of the glass waste storage canisters has been completed and documented in WSRC-TR-93-520.

Deflagration Analysis of DWPF Tanks - S. J. Hensel

The computer code DPAC, developed to determine the hypothetical pressure transient during an ITP deflagration, will be used to analyze potential DWPF deflagrations.

Thermal Evaluation of the 9965, 9966, 9967, and 9968 Shipping Packages - J. W. Jerrell, S. J. Hensel .

Revisions to the dimensions of the $9965,9966,9967$, and 9968 shipping packages are being incorporated into the thermal models and the SAR documentation is being completed. Benchmarking of the high temperature celotex thermal model continued.

Structural Analysis of Closure Cap Barriers - A Pre-test Study for the Bentonite Mat

The U. S. Environmental Protection Agency (EPA) recommended waste site cover system design capitalizes on the performance characteristics of both natural and man-made materials. The introduction of man-made geosynthetic materials increases performance capabilities of both hydraulic and structural characteristics of the cover system. This provides the cover system strength to maintain its integrity under greater stress than natural soils.

High Level Waste Simulation Package - M.V. Gregory .9

The 2H/ESP SPEEDUP model will be expanded to include all significant High level waste complex operations in at least a skeletal fashion. One of the four new elements (the $\mathrm{H}$-Area Waste Removal Tanks) has been completed. In addition, modeling of the ESP slurry pump seal leakage will be attempted.

Training on F-Canyon Ventilation Model - J. E. Aull . .9 A week-long training session was conducted for personnel in the Separations Engineering Group and the Environmental Air System Group on Bechtel's Dynamic Analysis Program (DAP) and the DAP model of the F-canyon ventilation system.

High Level Waste Model User Interface - J. E. Aull, K. L. Shanahan

The 2H/ESP SPEEDUP model was modified to read batch sequencing information that controls the sim-ulation as it runs.

SPEEDUP Installation on VAXstation - J. E. Aull, K. L. Shanahan .10 SPEEDUP was installed on a VAXstation within the SRTC VAXcluster. Models execute at approximately $60 \%$ the speed of the VAX 8810 , node SLLAB2.

\section{APPLIED STATISTICS \\ (R. C. Tuckfield, Manager)}

Environmental Monitoring Section's Data Analysis Program (EMDAP) Delivered - M. D.

Wise, R. C. Tuckfield, G. R. Morton, E. W. Jenkins

EMDAP is a menu-based interface to the EMS data bases which allows automated generation of predefined reports. EMDAP was made available to EMS users in early September. 
Aluminum Nitrate Testing at the Effluent Treatment Facility - M. D. Wise Addition of Aluminum Nitrate to the Wastewater Collection Tanks has been shown to improve the performance of the Effluent Treatment Facility(ETF) filters. Testing during FY93 has helped identify a predictive model of filter run capacity and areas of improvement to be investigated in FY94.

\section{APPLIED PHYSICS}

(C. E. Apperson, Manager)

\section{Methods Development- R. E. Pevey}

Programmer's Environment and Configuration Control - P. W. Wyatt

SCS has a software product (NPA_E, developed by Tom Amold in 1990-91) which unites the advantages of the UNIX utility "imake" and a configuration control system. The imake utility is PORTABLE. It allows a user to make Makefiles on a wide variety of platforms without worrying about the machine-dependent idiosyncracies of the UNDX utility "make". Makefiles are a labor-saving device for compiling and linking complicated programs, and imake is a labor-saving device for making Makefiles, as well as other useful software (like a description of a program's internal dependencies on included files). Tom originally wrote his NPA_E for C code to run on Sun-4's and RS6000's. In the past month, the NPA_E has been modified to handle C code on the Cray (using UNICOS) and on an SGI Indigo (using IRIX). It has also been modified to handle FORTRAN on a Sun-4. This means that large FORTRAN programs can be managed in much the same way that UNIX developers managed the development of $X$ - with order and planning in the way the code is controlled, updated, compiled, linked, and installed. It also means that Makefiles can be created and used by people who are not expert UNDX programmers.

\section{Criticality Methods and Analysis - J. F. Mincey}

Experimental Benchmark Descriptions - E.F. Trumble, R.L. Frost, J.B. Justice

Work continues on the development of experimental descriptions and benchmark specifications for criticality safety benchmark experiments in support of both on-site validation and a DOE sponsored, complex wide, Criticality Safety Benchmark Evaluation Working Group.

DOE Order 5480.24 Compliance - R. L. Reed

APG has submitted tables detailing SRTC facility level compliance with DOE Order 5480.24 and associated implementation plans for identified non-compliances. ESH\&QA has submitted them for WSRC management approval.

100 Area Fuel Consolidation Support Activities - R. L. Reed and S. Y. Lee

APG has performed calculations to assess the degree of subcriticality maintained in Assembly storage arrays proposed for the unirradiated fuel consolidation in K Area. Calculations for increased storage in Disassembly have been initiated.

100 Area Support Activities -Mark 42 Criticality - R. L. Reed Criticality potential of irradiated Mark 42 assemblies in P Area Disassembly Basin has been requested.

100 Area Support Activities -PVC Enclosures for K-15 Fuel - R. L. Reed

Evaluation of the criticality aspects of enclosing the K-15 Mark 22 fuel assemblies in PVC pipes before placing them in the borated fuel storage racks has been requested.

Technical Reviews: K Disassembly VTS Cleanup - R. L. Reed

The RED evaluation (RRD-RED-930306) of the criticality potential associated with VTS sludge removal was reviewed and approved. 
Technical Reviews: TA -93-0003-0001 (Loading of Borated Racks in 321-M with defueling ingots) - R. L. Reed .

A proposed Test Authorization to approve loading of defueling ingots into borated storage racks in 321-M was reviewed and comments provided to the author.

Tech. Reviews: Improved Storage of Corroding Mark 31A Slugs in L Area - R. L. Reed .16 The RED evaluation (RRD-RED-930343) of the criticality potential associated with modified storage of corroding Mark $31 \mathrm{~A}$ slugs in the L Disassembly basin was reviewed and approved.

Technical Reviews: Disassembly Basin Sludge Cleanup in L Area - R. L. Reed . .16 The RED evaluation (RRD-RED-930373) of the criticality potential associated with sludge removal activities in the L Disassembly basin was reviewed.

USF Waste Handling Facility NLM Studies - J. F. Zino, K. C. Okafor, and R. L. Webb .........................16 A study to recommend locations for NIMs within the Uranium Solidification Facility (USF) waste handling facility is nearing completion, and preliminary results have been released.

AMPX-77 Certification - K. A. Niemer

Certification of the AMPX-77 modular code system has begun.

Installation and Testing of SCALE4.1 - ORIGENS - J. H. Hightower The ORIGENS code of the SCALE4.1 modular system of computer codes has been installed on the CRAY machine.

\section{EXPERIMENTAL THERMAL HYDRAULICS \\ (D. R. Muhlbaier, Manager)}

Enhanced Waste-Tank Level Model - M. R. Duignan

Modeling of environmental effects on the waste level in the waste tank located in $\mathrm{H}$-area has been initiated.

FRR Spent Fuel Dry Storage Development - H. N. Guerrero

The Department of Energy has a program to develop dry storage as a means of storing Foreign Research Reactor (FRR) spent fuel in the interim period prior to acceptance of the fuel in a final repository. This is needed in view of the present plans to phase out Separations Area facilities and the continuing delivery of FRR spent fuel over a period of 10 to 15 years. The objective of the ETF portion of the program is to determine how one of the four commercial dry fuel storage canister designs can be adapted to meet thermal storage requirements of the FRR spent fuel.

Pilot Scale Demonstration of HEME Dissolution Process - Z H. Qureshi

The High Efficiency Mist Eliminators (HEME) used in the melter feed preparation process will be dissolved in a caustic solution for their ultimate disposal. A pilot-scale demonstration of this dissolution process will be conducted in the Thermal-Fluids Lab. This task is scheduled to be complete by June 94 .

ITP Filter Replacement Capability - A. C. Smith

This task will establish the capability to replace the ITP filters and dispose of the unusable filter.

Plasma Technology Users Facility - T. L. Spatz

A Plasma Technology User Facility has been proposed by Interim Waste Technology (IWT) and Office of Technology Development (OTD) to be set up at TNX. An existing plasma arc furnace has been donated by the South Carolina Research Authority (SCRA) at Charleston. The project is still in its infancy but the ultimate goal is to have a multi-purpose/multi-user plasma furnace. 
E7 Manual Orientation - T. J. Steeper .19

E 7 Manual Orientation has been completed for our section

Crossflow Filter Test - J. L. Steimke

A test loop for a crossflow filter has been designed and built.

Air Cooling of Glass Canisters - J. L. Steinke .20

A proposal was made to address technical questions for the Glass Waste Storage Building.

Proposal for Foaming Study - J. L. Steimke .0 .20

A proposal was made to address foaming concerns for the SRAT and SME.

Rectifier Operating Procedure - J. L. Steimke

The rectifier operating procedure is being revised.

Support to Low Level Mixed Waste Vitrification Program - J. C. Whitehouse 21 Instrumentation and Data Acquisition Systems were installed at the DOE/Industry Waste Vitrification Center at Clemson University. 


\section{Administrative}

\section{Scientific Computing Resource Center}

Table 1: SCRC Courses

\begin{tabular}{|c|c|c|}
\hline \multicolumn{1}{|c|}{ Course } & Students & Date \\
\hline \hline $\begin{array}{l}\text { Object Oriented Analysis and Design } \\
\text { (LNRVH072) }\end{array}$ & 12 & September 27-30 \\
\hline
\end{tabular}

Table 2: Facilities Utilization

\begin{tabular}{|l|c|c|c|}
\hline \multicolumn{1}{|c|}{ Name/Dept. } & Room/Application & $\begin{array}{c}\text { Students } \\
\text { Trained }\end{array}$ & Date \\
\hline \hline $\begin{array}{l}\text { Maureen Schilb } \\
\text { Analytical Lab } \\
\text { Sample Management \& Analysis }\end{array}$ & $\begin{array}{c}\text { IBM } \\
\text { Training on Environmental } \\
\text { Database }\end{array}$ & 8 & Sept. 2 \\
\hline Morgan Wise, SRTC & $\begin{array}{c}\text { VAX } \\
\text { Demo Environmental } \\
\text { Monitoring SAS Program }\end{array}$ & 2 & Sept. 13 \\
\hline $\begin{array}{l}\text { Harvey Reif, Contractor-Stone } \\
\text { Webster Engineering }\end{array}$ & $\begin{array}{c}\text { MAC/DOE Emergency Pre- } \\
\text { paredness Requirements }\end{array}$ & $\begin{array}{c}8 \\
\text { DOE Per- } \\
\text { sonnel }\end{array}$ & $\begin{array}{c}\text { Sept. 28 } \\
\text { Sept. }\end{array}$ \\
\hline Terry Williams, FMIS & MAC/CLS Training & 6 & Sept. 29 \\
\hline
\end{tabular}

Travel

Aug. 30-Sept. 3 R. W. Rathbun served as Registration Chair for the ANS ETD Topical Meeting in Charleston, SC.

Sept. 13-14 C. E. Apperson participated in the ANS Technical Program Comnittee paper review for the 1994 Reactor Physics Topical Meeting held in Knoxville, TN.

Sept. 18-23 R. L. Frost attended the ANS 1993 Topical Meeting on Physics and Methods in Criticality Safety Workshop in Nashville, TN.

Sept. 18-23 R. L. Webb attended the ANS 1993 Topical Meeting on Physics and Methods in Criticality Safety Workshop in Nashville, TN.

Sept. 19-24 C. E. Apperson attended the Westinghouse Employee Development Course \#967, Middle Managers Development Program, held in Pittsburgh, PA.

Sept. 19-23 R. L. Reed attended the ANS 1993 Topical Meeting on Physics and Methods in Criticality Safety Workshop in Nashville, TN.

Sept. 19-23 E. F. Trumble attended the ANS 1993 Topical Meeting on Physics and Methods in Criticality Safety Workshop in Nashville, TN. 
Sept. 19-22 T. G. Williamson participated as a member of the (ABET) engineering accreditation team at Idaho State University in Pocatello, ID.

Sept. 26-29 R. W. Rathbun participated in the Plutonium Burner Strategy Meeting at WEC in Monroeville, PA.

Sept. 29-Oct. 1 C. E. Apperson participated in the HE-SNF meeting hosted by B\&W Fuels Division in Las Vegas, NV.

\section{Presentations}

Sept. 12-17

M. R. Buckner presented a poster session titled "Strategies For Denaturing The Weapons Grade Plutonium Stockpile (U)" at the GLOBAL'93 International Conference and Technology Exhibition in Seattle, WA.

Sept. 19-20 J. F. Zino presented a paper titled "The Need For Coupled Differential And Integral Spectral Radiation Measurements (U)" at the ANS 1993 Topical Meeting on Physics and Methods in Criticality Safety Workshop in Nashville, TN.

Sept. 30 R. J. Gromada and S. J. Hensel presented the current status on high temperature celotex thermal model at Gaithersburg, MD. 
(J. R. Pelfrey, Manager)

\section{Engineering Modeling}

\section{Thermal Analysis of Glass Waste Storage Canisters - S. J. Hensel}

\section{Customer: DWPT}

Abstract: A preliminary thermal analysis of the glass waste storage canisters has been completed and documented in WSRC-TR-93-520.

The general purpose thermal analysis software $P /$ Thermal was used to determine the maximum glass temperatures for free standing canisters. The canisters were cooled by natural convection only. The energy was assumed to be uniformly deposited in one of two regions, the glass or the steel cylinder adjacent to the glass. Assuming energy deposition in the glass only and the ambient temperature to be $37.78^{\circ} \mathrm{C}\left(100^{\circ} \mathrm{F}\right)$, the glass temperature limit of $400^{\circ} \mathrm{C}$ is not exceeded for heat generation rates which are three times the $\mathbf{4 6 0}$ watts per cannister used as a design basis for the Glass Waste Storage Building. Depositing all of the energy in the steel resulted in even lower peak glass temperatures.

\section{Deflafration Analysis of DWPF Tanks - S. J. Hensel}

Customer: STS

Abstract: The computer code DPAC, deoeloped to determine the hypothetical pressure transient during an ITP deflagration, will be used to analyze potential DWPF deflagrations.

The DWPF tanks under consideration are significantly smaller than the ITP tanks previously analyzed with DPAC. The flame propagation model will be modified since the DWPF tanks do not contain center columns. These tanks contain numerous vent lines. Some lines are tank to tank while others act as vents to larger cell volumes. The various vent paths will be incorporated into the analysis as well as the friction effects during venting of the deflagration. Preliminary results should be forthcoming at the end of October.

Thermal Evaluation of the 9965, 9966, 9967, and 9968 Shipping Packages - J. W. Jerrell, S. J. Hensel

Customer: Packaging and Transportation Group

Abstract: Reoisions to the dimensions of the $9965,9966,9967$, and 9968 shipping packages are being incorporated into the thermal models and the SAR documentation is being completed. Benchmarking of the high temperature celotex thermal model continued.

Several minor changes to the package dimensions and materials have recently been made by the customer. Although the changes are estimated to have an insignificant impact on package temperatures, the models and analyses are being revised accordingly for incorporation into the Safety Analysis Report (SAR). Eliminating as many discrepancies as possible between the physical package and model may help to reduce the number of questions that arise during the approval process. Additionally, to insure that the package fiberboard temperature does not exceed $250^{\circ} \mathrm{F}$ and degrade, the internal source loading for the packages is being limited to $13 \mathrm{~W}(9965), 16 \mathrm{~W}(9966), 20 \mathrm{~W}$ (9967), and $23 \mathrm{~W}$ (9968). 
An estimated two-thinds of the documentation for the normal conditions of transport has been delivered to the customer for review. Analysis results are being included in the documentation as they are completed.

The high temperature celotex thermal model was benchmarked against furnace temperature data taken during testing of the 9971 package and the DT-18 package. $f$ vreement between the analysis using the proposed celotex thermal model and the test data was fair.

\section{Structural Analysis of Closure Cap Barriers - A Pre-test Study for the Bentonite Mat Demonstration Project - C. Gong \\ Customer: Environmental Restoration Department}

Abstract: The U. S. Environmental Protection Agency (EPA) recommended waste site cover system design capitalizes on the performance characteristics of both natural and man-made materials. The introduction of man-made geosynthetic materials increases performance capabilities of both hydraulic and structural characteristics of the cover system. This provides the cover system strength to maintain its integrity under greater stress than natural soils.

SCS has been asked to computationally model the mechanical behavior of the clay cap closure. The initial task is to carry out the Pre-Test numerical modeling of the Bentonite Mat Demonstration Project (BMDP).

According to the EPA-recommended closure cap design a waste site can either be covered with a single layer cap made of 36 inch of compacted soil (clay) or with a multilayer cap consisting of an upper vegetative layer underlain by a drainage layer over a low permeability layer.

The Environmental Restoration Department of WSRC is in the process of testing the composite clay cap barriers recommended by EPA. The Bentonite Mat Demonstration Project (BMDP) is a field demonstration study to determine the construction / installation requirements, permeability, and subsidence performance characteristics of a composite barrier. The composite barrier will consist of on-site sandy-clay blanketed by a bentonite mat and a flexible High Density Polyethylene (HDPE) liner (also called flexible membrane liner). Construction of one control test pad and three bentonite test pads are planned. The control test pad will be used to establish baseline data. Underneath the composite clay cap is a four-foot loose sand layer in which cavities will be created by evacuation of sand.

This study provides a mathematical model for the testing project. The mathematical model will be used to simulate the mechanical and structural responses of the composite clay cap during the testing processes. With sufficient field tested soil mechanical properties and cavity configurations, the mathematical model could predict the structural behavior of the clay caps in great accuracy. At present, the soil test data and the cavity configurations are not available. Based upon engineering experience and technical references, a set of nominal soil parameters have been selected. Since the configuration of the cavities created in the testing process is irregular and unpredictable, two extreme configurations are considered in this mathematical model, viz., the circular cavity and the infinitely long trench in the sand underneath the cap. This approach will provide bounds for the testing results.

An axially symmetric model is constructed for the cap covering circular cavities, and a plane strain model for the cap bridging the trenches. The two dimensional finite element mesh for both models are is icntical. The flexible membrane iiner is meshed with shell elements. The responses of the cap are calculated for circular cavities ranges from 3-foot to 12-foot in diameter and trenches widths from 3-feet to 10 -feet.

The loads upon the cap system are gravity and 2 psi pressure on the top surface of the cap. In both models the maximum deflection of the cap is at the center of the cavity and the deflection increases with the size of the cavity. The regions of maximum stresses and large deformations are in the vicinity of cavity edges and the center of the cavity. The maximum deflection for the 12-foot circular cavity model is 2.13 inches, while tha maximum deflection for the cap over the 10 -foot trench is 6.08 inches. The composite clay cap which spans over the 10-foot trench reaches its load carrying capacity. 
Though the results from the mathematical analysis demonstrate the credible structural behavior of the clay cap, realistic in-situ mechanical properties of materials are needed for a good mathematical model which can accommodate prediction for the actual cap behaviors.

Post-test investigation and analysis of the BMDP will provide feedback for the mathematical model. The finite element analysis model can be further improved with the input of test data. Further studies of the composite clay cap barrier are recommended.

\section{High Level Waste Simulation Package - M.V. Gregary}

\section{Customer: High Level Waste Manageme. it Division}

Abstract: The 2H/ESP SPEEDUP model will be expanded to include all significant High level waste complex operations in at least a skeletal fushion. One of the four new elements (the H-Area Waste Remooal Tanks) has been completed. In addition, modeling of the ESP slurry pump seal leakage will be attempted.

Rather than integrating in the detailed In-Tank Precipitation (ITP) model, the customer has requested that the existing SPEEDUP model encompassing the 2H Evaporator system and the Extended Sludge Processing (ESP) facility be expanded to include all the other significant elements in the high level waste processing complex. Initially, these new elements would be implemented in a "skeletal" form, just so the detailed, overall system connectivity would be correctly represented. In follow-on development, these new "black boxes" would be revisited in a staged manner in order to flesh out more detailed unit operation models.

For this initial "skeletal" model, four elements will be added to the existing model: the H-Area Waste Removal Tanks, the $1 \mathrm{H}$ Evaporator System, the F-Area Complex, and the New Waste Transfer Facility. The first element has been completed (implemented and fully tested). Though it is but one of the four new elements, the implementation of the H-Area Waste Removal Tanks "black. box" required the development of generalized front-end models which will accept feeds from anywhere in any combination for the ESP and ITP connections. This will allow the remaining "black boxes" to be hooked up more easily. The commitment has been made to complete all four new elements by 31 October.

In parallel to the above work, an effort will be made to add a dynamic slurry pump seal leak model to the existing ESP model. This is a new area of interest. The leakage dynamics can have a significant effect in three areas: upon the additional volume of tank farm inventory that needs to be decanted and disposed of, upon inhibitor addition requirements, and also upon the actual sludge composition as it is transferred to DWPF.

\section{Training on F-Canyon Ventilation Model - J. E. Aull}

\section{Customer: Separations Engineering, Environmental Air Systems}

Abstract: A week-long training session was conducted for personnel in the Separations Engineering Group and the Environmental Air System Group on Bechtel's Dynamic Analysis Program (DAP) and the DAP model of the F-canyon ventilation system.

A week-long training session was conducted for personnel in the Separations Engineering Group and the Environmental Air System Group on Bechtel's Dynamic Analysis Program (DAP) and the DAP model of the F-canyon ventilation system. Dr. Frank Chen of Bechtel, San Francisco provided the bulk of the training but I conducted a four hour session on enhancements to the DAP program, transfer of data for display on the Interactive Engineering Analyzer (IEA), and fundamentals of using the IEA. 


\section{High Level Waste Model User Interface - J. E. Aull, K. L. Shanahan}

Customer: High Level Waste Management Division

Abstract: The 2H/ESP SPEEDUP model was modified to read batch sequencing information that controls the simulation as it runs.

SPEEDUP models may have parameters input as part of the model source listing but this causes problems as any changes would force the user to edit and recompile the model source. But user revision of the source is tedious, time-consuming, and makes configuration control nearly impossible. Another approach is to use the External Data Interface (EDI) feature of SPEEDUP which calls FORTRAN routines which read the value of parameters from text files. The text files contain data such as the schedule for turning valves on and off and the composition of input streams. Other packages such as RS/1 can then be used to generate data input screens and to graph and permanently store the input data. A prototype for this type of user interface was added on to the 2H/ESP model.

\section{SPEEDUP Installation on VAXstation - J. E. Aull, K. L. Shanahan}

\section{Customer: High Level Waste Management Division}

Abstract: SPEEDUP was installed on a VAXstation within the SRTC VAXcluster. Models execute at approximately $60 \%$ the speed of the VAX 8810, node SLLAB2.

SPEEDUP problems tend to use a lot of CPU time. The VAX 8810 (SLLAB2) was the only VAX on the SRTC cluster where SPEEDUP could execute so it was installed on a VAXstation 3100 (SLVS14) that is also part of the cluster. As a baseline, we ran a problem using SLLAB2. It took 59 seconds with SLLAB2 in a fairly non-busy state. The same problem took 1:38 when it ran on the VAXstation with the data being stored on SLLAB2's disk. When two SPEEDUP jobs were run concurrently on SLLAB2, the elapsed time grew from 59 seconds to 1:28. The job still took 1:38 when it was run on the VAXstation with another SPEEDUP job running on SLLAB2. So from this we conclude that the VAXstation gives comparable performance to SLLAB2 when SLLAB2 is busy and even when SLLAB2 is not busy the VAXstation is running about $60 \%$ as fast as SLLAB2. 
Environmental Monitoring Section's Data Analysis Program (EMDAP) Delivered - M. D. Wise, R. C. Tuckfield, G. R. Morton, E. W. Jenkins

Customer: Environmental Monitoring Section (EMS)

Abstract: EMDAP is a menu-based interface to the EMS data bases which allows automated generation of predefined reports. EMDAP was made aoailable to EMS users in early September.

The Environmental Monitoring Section's Data Analysis Program (EMDAP) is a modular menu-based report generating program which allows user-friendly access to EMS data in Ingres databases through the SASO system. Standard EMS reports can be output, both on-screen and printed, based on user-defined data ranges. Through the combination of Ingres and SASO, EMDAP simplifies the reporting process and allows access to a broader base of users. In the process of developing EMDAP, several data consistency errors were identified by ASG which have since been fixed by EMS. EMDAP Version 1.0 was made available to EMS users in early September 1993. Documentation included with EMDAP consisted of a User's Manual, System Manager's Manual and Technical Specifications.

Aluminum Nitrate Testing at the Effluent Treatment Facility - M. D. Wise

Customer: High Level Waste Engineering/Cognizant Engineering Section

Abstract: Addition of Aluminun. Nitrate to the Wastewater Collection Tanks has been shown to improve the performance of the Effluent Treatment Facility(ETF) filters. Testing during FY93 has helped identify a predictive model of filter run capacity and areas of improvement to be investigated in FY94.

Addition of Aluminum Nitrate to the Wastewater Collection Tanks has been shown to improve the performance of the ETF filters. Three tests were conducted in the months of February, April, and September. Ine tests yielded data that validated earlier conclusions that the addition of Aluminum Nitrate to non-routine feed has a positive effect on the performance of ETF's submicron filtration unit. Performance was observed to increase from 30 to $309 \%$, depending on the season. The data also supports earlier conclusions that an optimal aluminum concentration exists in the range of $30-40 \mathrm{ppm}$, and concentrations above this range begin to retard filtration performance.

A rudimentary mathernatical model that would predict Stage 1 flux was also developed during FY93. The model allowed for a more concise comparison of filter test runs, as well as an increase in the efficiency of the testing program by allowing shorter test runs to be conducted. It is postulated that the model can be further optimized to include aluminum concentration and time of year as independent variables that determine Stage 1 flux.

The Applied Statistics Group is providing test planning and data analysis report to this continuing effort. Fiscal Year 1993 results have been summarized in WSRC-TR-93-513, coauthored by M. D. D. Goodman (HLWE/CES) and M. D. Wise (SRTC/ATS). 
APPLIED PHYSICS

(C. E. Apperson, Manager)

Methods Development- R. E. Pevey

Programmer's Environment and Configuration Control - P. W. Wyatt

Customer: Code Developers in General

Abstract: SCS has a software product (NPA_E, developed by Tom Amold in 1990-91) which unites the advantages of the UNIX utility "imake" and a configuration control system. The imake utility is PORTABLE. It allows a user to make Makefiles on a wide variety of platforms without worrying about the machinedependent idiosyncracies of the UNIX utility "make". Makefiles are a labor-saving device for compiling and linking complicated programs, and imake is a labor-saving deoice for making Makefiles, as well as other useful software (like a description of a program's internal dependencies on included files). Tom originally wrote his NPA_E for C code to run on Sun-4's and RS6000's. In the past month, the NPA_Ehas been modified to handle C code on the Cray (using UNICOS) and on an SGI Indigo (using IRIX). It has also been modified to handle FORTRAN on a Sun-4. This means that large FORTRAN programs can be managed in much the same way that UNIX developers managed the development of $\mathrm{X}$-- with order and planning in the way the code is controlled, updated, compiled, linked, and installed. It also means that Makefiles can be created and used by people who are not expert UNIX programmers.

Development of engineering applications often began without a means of managing the software in an ordered, modular fashion. This is particularly true of applications that were originally coded under operating systems which do not lend themselves to a development environment. Sometimes, you may still find applications consisting of few (perhaps one) large FORTRAN sources in a simple directory structure (or lack of structure).

On a system where a user's "own" space is limited, they may not even fit into your edit buffer. This situation was later addressed under UNIX with Makefiles. The Makefile is an input file for the UNIX executable "make." This utility uses other UNDX utilities to find sources, compile and link them, and deliver an executable somewhere. It may also sort and discover dependencies on included files, usually by using the $C$ preprocessor. This means that when you add a new (perhaps hidden) dependency to a source, the "make" utility will sense which sources need to be recompiled and will do the operation for you. To update the dependencies, you need only type "make depend". To recompile and linkwith the new sources and dependencies, you must type the name of whatever is new (say header new_header.h) into the (portable) imake input file (Imakefile) and type "make Makefile", followed by "make depend", and "make". The Imakefile is simple and has none of the Makefile's annoying dependencies on TABs. If you change a source that already appears in the Makefile and its dependency file (".depends"), just type "make".

So why not just use "make", which is a powerful tool, to manage code development? There are several reasons. In the first place, "make" does not recognize conditionals. So to port from one platform to another, you must edit each Makefile to suit the new platform. If you have a lot of Makefiles, you must do a lot of editing. But imake, which uses a series of datafiles that allow conditionals, requires little editing (which in the case of the NPA_E is the responsibility of the NPA_E custodian - not the user). Also, "make" has no flow control and any Makefile dependencies on headers are inherently nonportable. We can limit editing to a few key points with imake and take most of the burden off the user. The user will usually have to tailor some of the NPA_E directory structure to be mnemonically named. Also, the prototype library structure (two user libraries delivered to a single executable) may not be sufficiently general for everybody. 
Tom Amold's NPA_E combines configuration control with imake (which he edited and whose data files like Imake.tmpl, Project.tmpl, etc., he edited extensively). There is a baseline directory featuring places for the modified imake and its data files, two suites of Bourne shells layered over imake, source locations, anchitecture-dependent residences for object code and executables, and delivery points for "finished" stuff. The user creates a "workspace", which is a mirror image of the baseline but with certain simplifications. The imake delivery and Tom's ".ws" and "ws" shells are not copied into the workspace. Nor is any unnecessary object code copied from the baseline to the workspace. Instead, such resources are "automatically" pointed to with soft links when a.depends is created. This reduces the likelihood of error and conserves disk space. Also, Imakefiles for "standard" directories like "lib" are copied into the workspace. The user may create other directories (for new libraries or executables) with one of the "ws" shells. Initial Makefiles are also created at this time. The user may then copy sources (including headers) out of the baseline or may invent new ones. Each time new ones are invented, the Imakefile must be edited and the local Makefile must be rebuilt with "make Makefile". Then the dependencies on headers (the.depends file, which starts out empty) must be updated with "make depend". Typing "make" creates a new executable, and "make install" delivers it to a point where it may be run from outside the workspace. The dependencies are discovered with the "ws_srcdepend" shell, which replaces the imake releases's "makedepend" utility, and searches for include files with the $C$ preprocessor. The NPA_E has been modified for use with FORTRAN sources on the Sun- 4 so that these may be processed with the $C$ pre-processor just like $C$ sources.

Tom included many useful utilities in the two groups of Bourne shells. Some are accessed from outside the NPA_E (workspace). Others may only be used inside it. Sources may be copied or checked out from the baseline. They may be checked into the baseline by "authorized" users. The baseline itself is typically protected by limiting both ownership and write permission. There are utilities for quick comparisons between the baseline and the workspace, for importing and linking blocks of new code, identifying who has something checked out (and thereby denied to other users until checked back in), and for quickly showing what local files are new, or different from, or the same as the baseline. This automates a great deal of what is sometimes done administratively with oth $x$ r configuration control systems. What might well be more important is that it could encourage the use of mechanically generated Makefiles (and a code structure that mirrors a baseline template) among programmers who are not experts in constructing Makefiles on multiple platforms. It would be interesting to extend the NPA_E from its prototype status to use in managing someone's engineering application.

\section{Criticality Methods and Analysis - J. F. Mincey}

\section{Experimental Benchmark Descriptions - E.F. Trumble, R.L. Frost, J.B. Justice}

\section{Customer: C.E. Apperson, APG}

Abstract: Work continues on the development of experimental descriptions and benchmark specifications for criticality safety benchmark experiments in support of both on-site validation and a DOE sponsored, complex wide, Criticality Safety Benchmark Evaluation Working Group.

The experiment description and benchmark specification for the unmoderated portion of the Phase I plutonium "button" arrays carried out at Lawrence Livermore were completed. These writeups were included in the first draft of a DOE Handbook on Evaluated Criticality Safety Benchmark Experiments which was published on October 1, 1993.

Work has been started on the moderated portion of Phase I, as well as on both Phase II and III of these experiments which will be included in the next draft of the DOE Handbook to be issued next fall. 


\section{DOE Order 5480.24 Compliance - R. L. Reed}

Customer: Ken Yates, ESH\&QA

Abstract: APG has submitted tables detailing SRTC facility level compliance with DOE Order 5480.24 and associated implementation plans for identified non-compliances. ESHEQA has submitted them for WSRC management approval.

ESH\&QA provided a list of compliance requirements for DOE Order 5480.24, "Nuclear Criticality Safety," to SRS organizations responsible for criticality safety at SRS facilities. The requirements as they pertain to SRTC facilities were reviewed by APG personnel. The preliminary tables of compliance and noncompliance were reviewed by numerous SRTC personnel, including the Criticality and Accountability Review Committee to assure accuracy and completeness. APG has submitted to ESH\&QA

1. Requested table indicating for SRTC facilities:

- Documents and procedures that ensure compliance with the order,

- Items of noncompliance

- Activities proposed or underway to improve compliance.

2. Implementation plans to correct the noncompliances

- Analyses are needed of NIM locations in SRTC

- Improvements in testing of NIM systems to comply with ANS 8.3 recommendations for alarm bell audibility.

ESH\&QA has submitted the complete SRS compliance assessment package to WSRC management for approval.

100 Area Fuel Consolidation Support Activities - R. L. Reed and S. Y. Lee

Customer: Marc Rosser (RRD/RED)

Abstract: APG has performed calculations to assess the degree of subcriticality maintained in Assembly storage arrays proposed for the unirradiated fuel consolidation in $\mathrm{K}$ Area. Calculations for increased storage in Disassembly have been initiated.

Proposals have been made (and are being studied) to increase the fuel storage capability in both Assembly Area and Disassembly Area of 105-K.

Strong consideration has been given to a proposal to relocate borated concrete fuel storage racks to $\mathrm{K}$ Area to increase the total unirradiated fuel storage capacity. Questions were raised about the protection available to assemblies in the racks during seismic events or severe weather (tornadoes, hurricanes) and assurances that assemblies will remain intact in the borated racks during such events. Under a task plan (TP 93-006-I-E-1), APG performed HRXN-KENO calculations to determine the critically safe number of Mark 22 fuel assemblies in a regular rectangular array outside the borated concrete storage rack.

Without moderation, a very large number $(>500)$ of fuel assemblies may be arrayed without attaining criticality. With moderation, no more than four assemblies should be allowed in a grouping, consistent with current Technical Specification limits. Variation in the lithium content of the outer targets of Mark 22 fuel assemblies is evident, but is small. Crushing the fuel assemblies increases reactivity of a dry array, but decreases reactivity of a moderated array since crushing effectively reduces the amount of moderator in the assembly array. For the arrays considered, optimum moderation is provided by full density water. Moderators such as heavy water were not considered since their presence in Assembly Area in vicinity of storage racks is not credible. A report (SRT-CMA-930065) documenting these calculations has been drafted and is in review. 
Means of increasing the Disassembly capacity for fuel storage include increasing the number of assemblies stored in a slot in the horizontal storagt racks. APG has agreed to examine the changes in subcriticality margin from current storage configurations and the means proposed to ensure maintenance of a minimum margin of safety. A task plan (TP 93-006-I-E-1) has been written and approved to perform the study, utilizing the HRXN-KENO and MGBS-TGAN-KEFF combinations of computer codes. The calculations are being initiated.

\section{Area Support Activities -Mark 42 Criticality - R. L. Reed}

\section{Customer: Marc Rosser (RRD/RED)}

Abstract: Criticality potential of irradiated Mark 42 assemblies in P Area Disassembly Basin has been requested.

Evaluation has been requested by RED of the criticality potential associated with array storage of the irradiated Mark 42 assemblies in P Area. The concern centers around the actinides, such as curium and americium, generated by neutron absorption in plutonium. Even though the plutonium content of the irradiated Mark 42 assemblies is now far too little to be of criticality concern by itself, some of the irradiation daughter products, such as $242 \mathrm{mAm}$, are much more reactive than plutonium and an evaluation is desired. APG has agreed to perform the evaluation.

\section{Area Support Activities -PVC Enclosures for K-15 Fuel - R. L. Reed}

\section{Customer: Marc Rosser (RRD/RED)}

Abstract: Evaluation of the criticality aspects of enclosing the K-15 Mark 22 fuel assemblies in PVC pipes before placing them in the borated fuel storage racks has been requested.

The Mark 22 fuel assemblies designated for the K-15 charge were previously in a reactor and thus are slightly contaminated. Concerns about long-term storage of fuel on hangers in Final Storage has prompted examination of methods to place the K-15 fuel in borated fuel storage racks. The fuel is currently in plastic sleeves (for contamination control). The plastic sleeves are not expected to remain intact during insertion into a borated rack storage location. APG has agreed to evaluate the criticality aspects of placement of Mark 22 fuel into sealed PVC containers to provide intact contamination control throughout handling during storage relocation.

\section{Technical Reviews: K Disassembly VTS Cleanup - R. L. Reed}

\section{Customer: M. A. Rosser (RED)}

Abstract: The RED evaluation (RRD-RED-930306) of the criticality potential associated with VTS sludge removal was reviewed and approved.

Initial sludge removal in the K Disassembly Basin will relocate the sludge from VTS to the Monitor Basin. Based on analytical results of sludge sample contents, there is insufficient fissionable material in the VTS basin at the isotopic composition of the fissile and fissionable materials in the aqueous mixture in the basin to result in a criticality. The evaluation used a number of conservatisms, such as using the maximum isotopic concentration of multiple sample results and deliberately underestimating effects of absorbers (such as U-238 and iron) in the sludge. Comments and suggestions for evaluation improvement were provided to and implemented by the evaluation author. SRT-CMA-930049 documents the APG review. 
Technical Reviews: TA -93-0003-0001 (Loading of Borated Racks in 321-M with defueling ingots) - R. L. Reed

\section{Customer: G. F. Couture, RMET}

Abstract: A proposed Test Authorization to approve loading of defueling ingots into borated storage racks in 321$M$ was reviewed and comments provided to the author.

A proposed Test Authorization to approve loading of defueling ingots into borated storage racks in 321-M was reviewed. The technical basis of the TA is an NCSA (WSRC-RP-93-321-214A) previously reviewed and approved by APG. Comments provided to the author concerned mainly the presentation and clarity (intent) of the TA material rather than technical issues. The APG review is documented in SRT-CMA-930051.

\section{Technical Reviews: Improved Storage of Corroding Mark 31A Slugs in L Area - R. L. Reed}

\section{Customer: M. A. Rosser (RED)}

Abstract: The RED eoaluation (RRD-RED-930343) of the criticality potential associated with modified storage of corroding Mark 31A slugs in the $L$ Disassembly basin was reoiewed and approved.

Although it has been previously established that Mark 31 slugs in slug buckets are critically safe in any arrangement, an evaluation was performed to support the enclosure of each slug bucket in a closed container so that corroding material can not escape to the basin environment. The evaluation depended on comparisons of material fissile contents in the slugs and comparisons with standard subcritical mass and concentration limits from TID-7016. The comparisons to the TID-7016 data required extrapolation of TID-7016 curves outside their stated ranges of applicability. APG performed HRXNANISN calculations to verify the conservatism of the extrapolations made. SRT-CMA- 930055 documents the APG review, including the calculational results.

\section{Technical Reviews: Disassembly Basin Sludge Cleanup in L Area - R. L. Reed}

Customer: M. A. Rosser (RED)

Abstract: The RED evaluation (RRD-RED-930373) of the criticality potential associated with sludge removal activities in the $L$ Disassembly basin was reviewed.

The sludge sample results for L Disassembly Basin were evaluated with the same methodology previously employed in RRD-RED-930306 to show that sludge removal in K Disassembly is critically safe. Insufficient fissile mass is in L Disassembly Basin to support a critical situation. The APG review concurs with the evaluation. SRT-CMA-930065 has been drafted to document the APG review.

\section{USF Waste Handling Facility NIM Studies - J. F. Zino, K. C. Okafor, and R. L. Webb}

\section{Customer: NMPD}

Abstract: A study to recommend locations for NIMs within the Uranium Solidification Facility (USF) waste handling facility is nearing completion, and preliminary results have been released.

In -upport of the design and construction of the USF waste handling facility, scoping studies have been completed that deal with the placement of Nuclear Incident Monitors (NIMs) within the facility. The preliminary results were released in SRT-APG-930085 and recommended two NIM pair locations. The analyses required for the final report has become quite involved due to nature of the facility many different materials will be handled and a number of different fission sources need to be considered. The final study is nearing completion and the recommendations of the preliminary report have largely been upheld, though it has been necessary to make a minor adjustment to the location of one NIM pair. A final report is expected by mid-November. 


\section{AMPX-77 Certification - K. A. Niemer}

Customer: Applied Physics Group

Abstract: Certification of the AMPX-77 modular code system has begun.

AMPX-77 is a modular code system for generating coupled multigroup neutron-gamma cross section libraries from ENDF-B data. AMPX-77 was written at Oak Ridge National Laboratory. It will be used for Criticality and Radiation Shielding analyses.

Certification of the forty-seven AMPX-77 modules has begun. The modules have been divided into three groups. Group 1, consisting of eight modules, is scheduled to be certified by January 1, 1994.

\section{Installation and Testing of SCALE4.1 - ORIGENS - J. H. Hightower}

\section{Customer: Applied Physics Group}

Abstract: The ORIGENS code of the SCALE4.1 modular system of computer codes has been installed on the CRAY machine.

ORIGENS is one of the codes from the Oak Ridge National Laboratory SCALE4.1 modular system of computer codes. It has been installed on the CRAY machine and testing is in progress. During the process, ORIGENS data libraries were built in order to run some of the test problems. Testing of ORIGENS should be complete within a couple of weeks. 


\section{Enhanced Waste-Tank Level Model - M. R. Duignan}

\section{Customer: High Level Waste Engineering}

Abstract: Modeling of environmental effects on the waste leoel in the waste tank located in H-area has been initiated.

With the increased sensitivity of waste level measurements in the waste tanks, located in H-Area, level changes have been recorded which are unexplained. An unexplained change of one (1) inch in the waste level is a reportable event. Qualitative observations indicate that much of the unexplained level change may be explained by environmental effects, i.e., changes in level due to changes in atmospheric pressure, temperature, and relative humidity. Quantitatively, some of the level changes have been explained by using a model that indicates the thermal expansion of the tanks' contents (but the contents are assumed to consist of only supernate). Unfortunately, that model does not work for all tanks. That model is limited in scope, but can be made more accurate by incorporating other changes which occur because of environmental changes. To this end, development began on a more extensive model to determine the waste level changes in the H-Area Tanks. In this way, reported unexplained level changes will be more meaningful. The projected completion of this work is February 2, 1994.

\section{FRR Spent Fuel Dry Storage Development - H. N. Guerrero}

\section{Customer: Ray Conatser, Technology Programs}

Abstract: The Department of Energy has a program to deoelop dry storage as a means of storing Foreign Research Reactor (FRR) spent fuel in the interim period prior to acceptance of the fuel in a final repository. This is needed in view of the present plans to phase out Separations Area facilities and the continuing delivery of FRR spent fuel over a period of 10 to 15 years. The objective of the ETF portion of the program is to determine how one of the four commercial dry fuel storage canister designs can be adapted to meet thermal storage requirements of the FRR spent fuel.

The thermal-hydraulic development task was initiated during this monthly reporting period. The initial task is a scoping analysis of the application of the commercial dry storage concepts to aluminum research reactor type spent fuel. For the development work on four commercial canister designs, the finite element analysis program, FIDAP, will be utilized for its facility of application to irregular geometries and three-dimensional modeling. After an optimum design has been reached, the finite difference code, COBRA, previously used in licensing the commercial designs, will be used for an independent design verification. The initial FIDAP analysis involves modeling an unmodified NUHOMS-24 P horizontal canister. A $180^{\circ}$ sector model with 12 fuel sleeves and fuel elements has been generated and has been successfully run for a few simple cases.

Work has also been initiated in designing an electrically heated MTR type fuel element mockup. Plans are to pass direct current through 0.050 -inch thick aluminum plates in order to ideally simulate thermal conductivity and thermal emissivity properties of the aluminum fuel plates. The fuel element mockup will be utilized to obtain basic thermal characteristic information required by FIDAP and COBRA, such as effective thermal conductivity, heat transfer coefficients, and friction factors. A second element of the experimental program will then be the fabrication and testing of a mockup section of a canister sufficient to simulate a full size canister with fuel elements. 


\section{Pilot Scale Demonstration of HEME Dissolution Process - Z H. Qureshi}

\section{Customer. DWPT}

Abstract: The High Efficiency Mist Eliminators (HEME) used in the melter feed preparation process will be dissolved in a caustic solution for their ultimate disposal. A pilot-scale demonstration of this dissolution process will be conducted in the Thermal-Fluids Lab. This task is scheduled to be complete by June 94.

The Defense Waste Processing Technology (DWPT) Section of SRTC has identified several tasks to be performed by the Experimental Thermal-Fluids Group during FY94. One of the high priority tasks is to completely develop the HEME dissolution process on a prototypical scale. Prior studies of the process were made on a bench scale with mixed success. A major aspect of the proposed demonstration tests is to study the effects of mechanical agitation on the dissolution process. A preliminary technical and cost proposal was prepared for DWPT's review and input. The Task Technical Plan is under preparation now. It is anticipated that the task will be complete by the request date of June 94.

\section{ITP Filter Replacement Capability - A. C. Smith}

Customer: ITP

Abstract: This task will establish the capability to replace the ITP filters and dispose of the unusable filter.

The EPA variance has been approved. Work has resumed on those items which were deferred because of budget limitations at the end of FY93. These include the filter box design review, box fabrication, SWDF safety assessment and crane access drawing revision. The design review cannot take place until supporting testing is completed at TNX. The schedule is being revised to reflect the influence of the benzene testing delays.

\section{Plasma Technology Users Facility - T. L. Spatz}

Customer: Interim Waste Technology (IWT) and Office of Technology Development (OTD)

Abstract: A Plasma Technology User Facility has been proposed by Interim Waste Technology (IWT) and Office of Technology Development (OTD) to be set up at TNX. An existing plasma arc furnace has been donated by the South Carolina Research Authority (SCRA) at Charleston. The project is still in its infancy but the ultimate goal is to have a multi-purpose/multi-user plasma fumace.

A literature search and meetings have been ongoing to establish an understanding of both the existing plasma arc furnace and the intended uses of the furnace. The two may not be compatible in their present form and the ETF group hopes to be actively involved in the retrofitting process.

\section{E7 Manual Orientation - T. J. Steeper}

Customer: Safety Technology Department

\section{Abstract: $E 7$ Manual Orientation has been completed for our section}

Orientation was provided to our department on the Conduct of Engineering and Technical Support Manual (E7) this month. Five people were oriented; Jim Herman oriented the remainder of the persons in the department. 


\section{Crossflow Filter Test - J. L. Steimke}

\section{Customer: DWPT}

Abstract: A test loop for a crossflow filter has been designed and built.

In preparation for delivery to the Defense Waste Processing Facility, slurry from Tank 49 will be washed in a filtering process where the filter retains solids in the flow loop and liquid is removed and replenished with wash water. Filter technology is key to this process. A ten foot long Du Pont crossflow filter will be tested in vertical orientation with simulated waste slurry in the Thermal Fluids Laboratory (TFL). This test will determine the effectiveness of filtering the slurry, of back-pulsing to remove solids from the surface of the filter, and of cleaning the filter. The test will also produce washed feed for downstream semi-works processes, such as the one-fifth scale PHEF, to be performed at TNX.

With the exception of connection to 80 psig building air, the vertical filter test loop has been completed in the Thermal Fluids Laboratory by C. M. Hart's team. As soon as the connection is made, shakedown of the loop will begin with distilled water. Irradiated simulated waste slurry (not a radiation hazard) will arrive for testing in a week.

\section{Air Cooling of Glass Canisters - J. L. Steimke}

\section{Customer: DWPT}

Abstract: A proposal was made to address technical questions for the Glass Waste Storage Building.

Canisters containing glassified waste will be held in the Glass Waste Storage Building. They will be cooled in air by a combination of forced convection and natural convection, which is called mixed convection. A computational fluid dynamics code will be ordered to analyze heat transfer for the glass canisters. However, the vendor of the code admits that there would be large uncertainties if the code were applied to this mixed convection problem unless there were experimental data for tuning. I prepared a proposal for the TFL to run two experiments. The first experiment would measure heat transfer coefficients for a full scale single canister. The second would measure temperature and air flow distributions for two dozen scaled down canisters connected in parallel.

\section{Proposal for Foaming Study - J. L. Steimke}

\section{Customer: DWPT}

Abstract: A proposal was made to address foaming concerns for the SRAT and SME.

During the course of processing high level waste, chemical mixtures are boiled in the Sludge Receipt and Adjustment Tank (SRAT) and the Slurry Mix Evaporator. Tests with simulated waste have indicated that foaming and carryover are problems. I prepared a proposal for the TFL to address these problems. The first sub-task would be benchtop scale tests to measure the effect on foaming of boilup rate, mercury or noble metals in the waste and vessel diameter. The second sub-task would be a vendor literature survey for probes to measure foam height. The third sub-task would the testing of foaming in a roughly quarter linear scale model of a SRAT.

\section{Rectifier Operating Procedure - J. L. Steimke}

Customer: Thermal Fluids Laboratory

Abstract: The rectifier operating procedure is being revised.

Six large rectifiers are used as a power sources for experiments in the Thermal Fluids Laboratory. The rectifiers are presently shut down awaiting a new operating procedure which is being revised to make it consistent with the Employee Safety Manual (8Q) and the Conduct of Operations Manual (2S). 


\section{Support to Low Level Mixed Waste Vitrification Program - J. C. Whitenouse}

\section{Customer: DWPT}

Abstract: Instrumentation and Data Acquisition Systems were installed at the DOE/Industry Waste Vitrification Center at Clemson University.

Simulated low level mixed wasie (LLMW) streams are being vitrified in two pilot scale melters, under a SCUREF contract, at Clemson's Environmental Systems Engineering School. ETF is supporting this effort by supplying instruments and a Data Acquisition System (DAS). To date, two melters have been instrumented. Test runs with M-Area simulated waste were recently completed in both melters. The instrumentation and DAS performed well, providing useful information on melter performance. Work was recently completed instrumenting the off-gas system for one of these melters. This additional instrumentation will be used to characterize the performance of the off-gas system. 


\section{L1100, Scientific Computations \\ Melvin R. Buckner \\ Section Manager \\ 773-A A-230 - 5-3149 \\ Parent Organization: \\ L1000 - Nuclear Rx Tech \& Sci Comp}

Administrative Secretary: Susie Gibson McKinney

773-A A238 - 5-1102

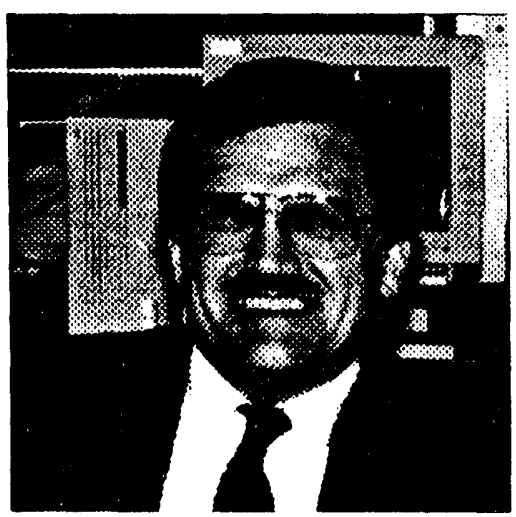

L1110 Compliance Mgmt Technology

Ames, Philip L

5

Gillespie, Lisa Ann

Senior Sec

773-42A 184

$5-8462$

.LSE-Prof.

.773-42A 151

$5-8199$

Krieger, John W.

.Sr Scientist A

$.773-42$ A 150

$5-8201$

..Assoc Scientist

.773-42A 149

$5-8209$

..Scientist.

773-42A 152

5-8204

L1120 Computing Technology

Beckmeyer, Russell R

10

Admin Clerk

773-42A 157

$\begin{array}{ll}. .773-42 A & 179\end{array}$

5-7172

$5-7386$

5-4192

...LSE-Prof

$.773-42$ A 114

Grove, Constance Rae

.Senior Engineer A

.773-42A 171

Mansour, Khalid A.

Senior Engineer A

$.773-42$ A 181

..Scientist......................................................773-42A 118

McGrath, Marybeth.

...Fellow Scientist.

$.773-42$ A 129

..Prin Eng

$.773-42$ A 127

...exp Experienced..........................................773-42A 173

704-2S N/A

$.773-42 \mathrm{~A} \quad 180$

Gen Clerk

$.773-42 \mathrm{~A} \quad 120$

Sr Fellow Sci...

$.773-42$ A 112

$.773-42 A \quad 138$

Sr Scientist .

$.773-42$ A 117

.773-A A-230

.773-42.A 126

LSE-Prof...

$.773-42 \mathrm{~A} \quad 178$

$5-5311$

5-5157

5-1111

5-8347

5-5133

5-5613

7-1086

5-5060

5-5147

5-8087

5-5159

5-1173

5-3149

5-1785

5-9780

Assoc Comp Spc

Apperson, Courtney $\mathrm{E}$

25

Assoc Engineer

.773-22A 11

..773-22A 10

$.786-1 \mathrm{~A} \quad 8$

Senior Engineer

.735-A B001

Cefus, Gregory R

Engineer

$773-42 A \quad 145$

.773-22A 11

.786-1A 6

..786-1A 9

..773-22A 06

.773-42A 173

$\begin{array}{lll}.773-42 A & 122\end{array}$
5-3899

5-3406

5-5626

5-1011

5-2520

5-2718

5-8195

5-5864

5-5526

5-4546

5-5145 


\begin{tabular}{|c|c|}
\hline 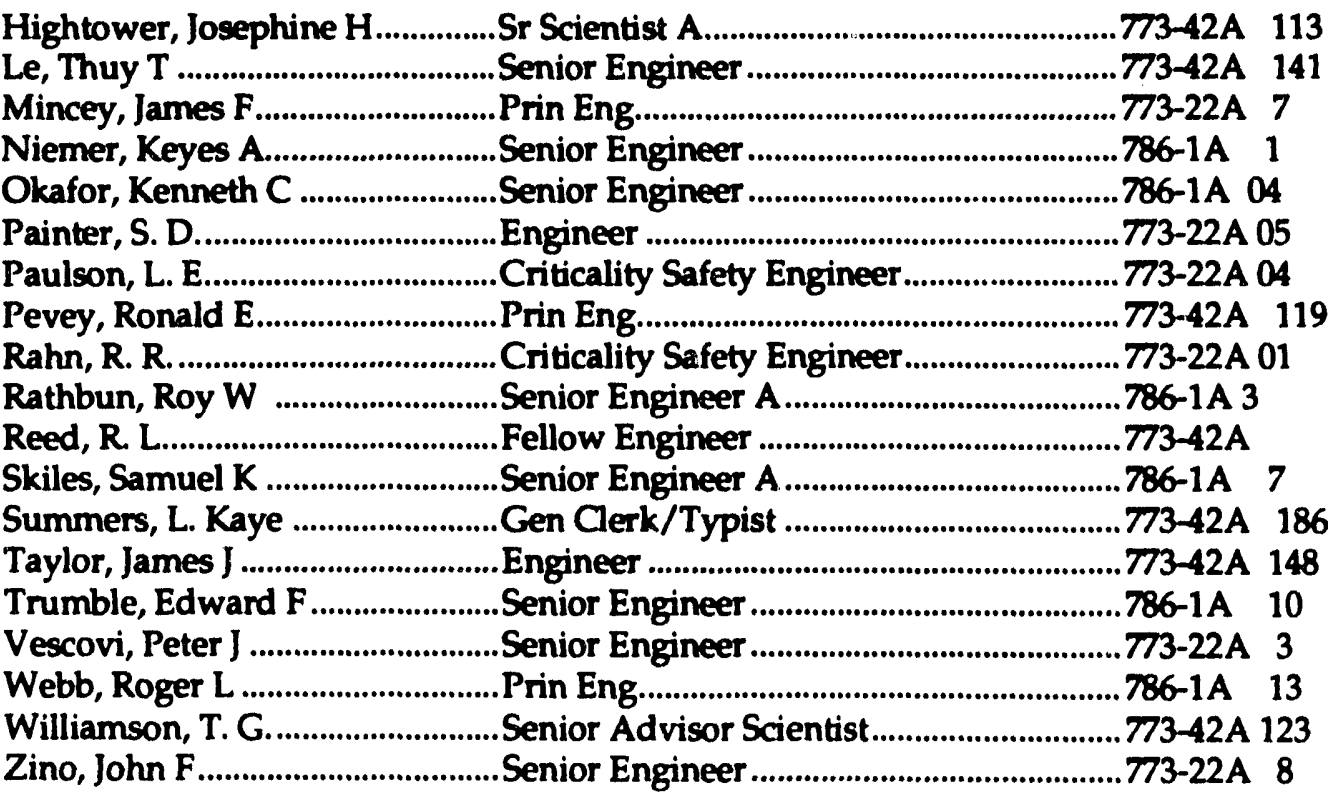 & $\begin{array}{l}5-8210 \\
5-5300 \\
5-2718 \\
5-2622 \\
5-8194 \\
5-5993 \\
5-4650 \\
5-1611 \\
5-8230 \\
5-8232 \\
5-0000 \\
5-1977 \\
5-8211 \\
5-5323 \\
5-4196 \\
5-3335 \\
5-8459\end{array}$ \\
\hline
\end{tabular}

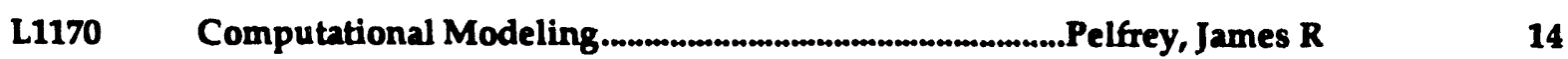

Aull, John E .................................Sr Scientist A.............................................773-42A $144 \quad$ 5-2288

Davis, Ricardo C.............................Scientist ....................................................773-42A $137 \quad 5-5172$

Gong, Chung.................................Prin Eng.....................................................773-42A $154 \quad 5-3167$

Gregory, Michael V ........................Sr Advisory Eng.............................................773-42A $142 \quad 5-3696$

Hammer, Kim E.............................Senior Engineer...........................................773-42A 115 5-2677

Hensel, Steve J................................Senior Engineer.........................................773-42A 155 5-5094

Jerrell, Jeffrey W .............................Senior Engineer..........................................773-42A $153 \quad$ 5-1727

Wolf, Ralph J .................................Sr Scientist A...........................................773-42A $136 \quad 5$ 5-5158

Wyatt, Paul W............................... Fellow Engineer .........................................773-42A $116 \quad$ 5-5132

\section{L1155 Applied Statistics.............................................................Tuckfield, R. Cary}

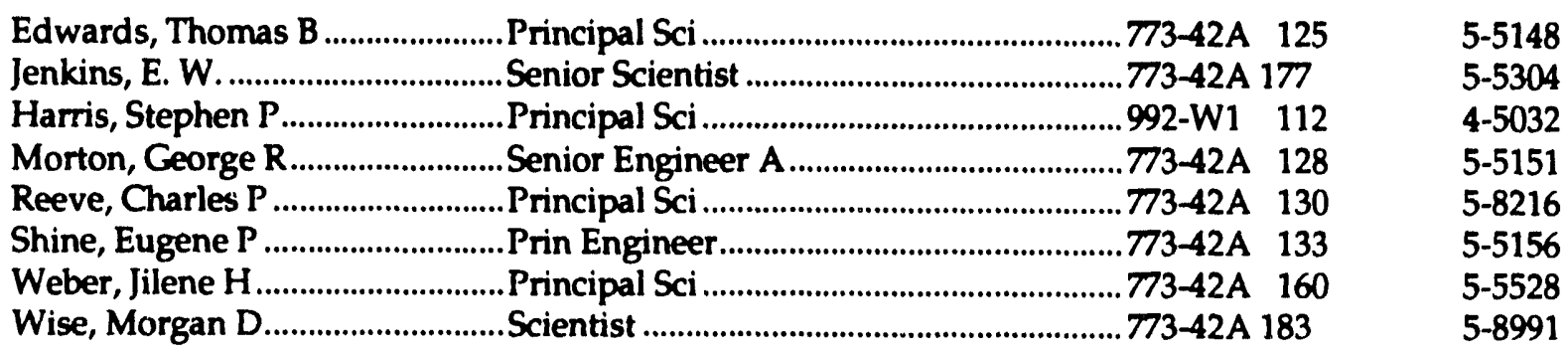




\section{Distribution}

Adams, R. L., 703-A

Ades, M. J., 992-1W

Ames, P. L., 773-42A

Antaki, G. A., 707-35B

Apperson, C. E., 773-42A

Aylward, R. S., 992-4W

Beckmeyer, R. R., 773-42A

Benton, F. D., 707-C

Beranek, F., 773-A

Bickford, D. F., 773-A

Bickford, W. E., 773-41A

Bickley, J. D., 723-A

Capeletti, T. L., 773-41A

Cox, J. C., 247-F

Crowley, D. A., 773-11A

Ebra, M.A., 992-4W

Franks, R. K., DOE, 773-41A

Graves, W. E., 773-42A

Green, D. J., 235-H

Halverson, J. E., 773-63A

Hitchler, M. J., 992-1W

Howell, J. P., 773-41 A

Iverson, D. C., 704-29S

Jantzen, C., 773-A

Jordan, J. F.,735-15A

Katonak, P. R., 773-51A

Kennedy, W. N., 707-49B

Knight, F. D., Brookhaven 32

Lee, M. W., 773-43A
Losey, D. C., 707-C

Louthan, M. R., 773-A

Maryak, M. E., 730-B

McCrosson, F. J., 773-41A

Morgan, M. J., 773-A

Muhlbaier, D. R., 786-5A

Opperman, E. K.,305-2A

Orebaugh, E. G., 773-43A

Ortaldo, J. F., 704-S

Patterson, J. R., DOE, 703-41A

Pelfrey, J. R., 773-42A

Plodinec, M. J., 773-A

Randall, E. C.,992-1W

Rankin, D. T., 773-A

Revolinski, S. M.,992-2W/439

Riechman, A. F. , 773-A

Stephens, K. W., 992-1W

Thiessen, C. W., 773-A

Thompson, G. P., 992-2W

Tran, T. M., DOE, 703-41A

Tuckfield, R. C., 773-42A

Veldman, J. P., 723-A

Whitney, M., 305-2A

Williamson, T. G., 773-42A

Wolfe, C. R., 773-A

Wooten, L. A., 992-1W

Wright, S. R., DOE, 703-41A

Yau, W. W. .3., 773-41A

Technical Information Management, 703-43A (2) 

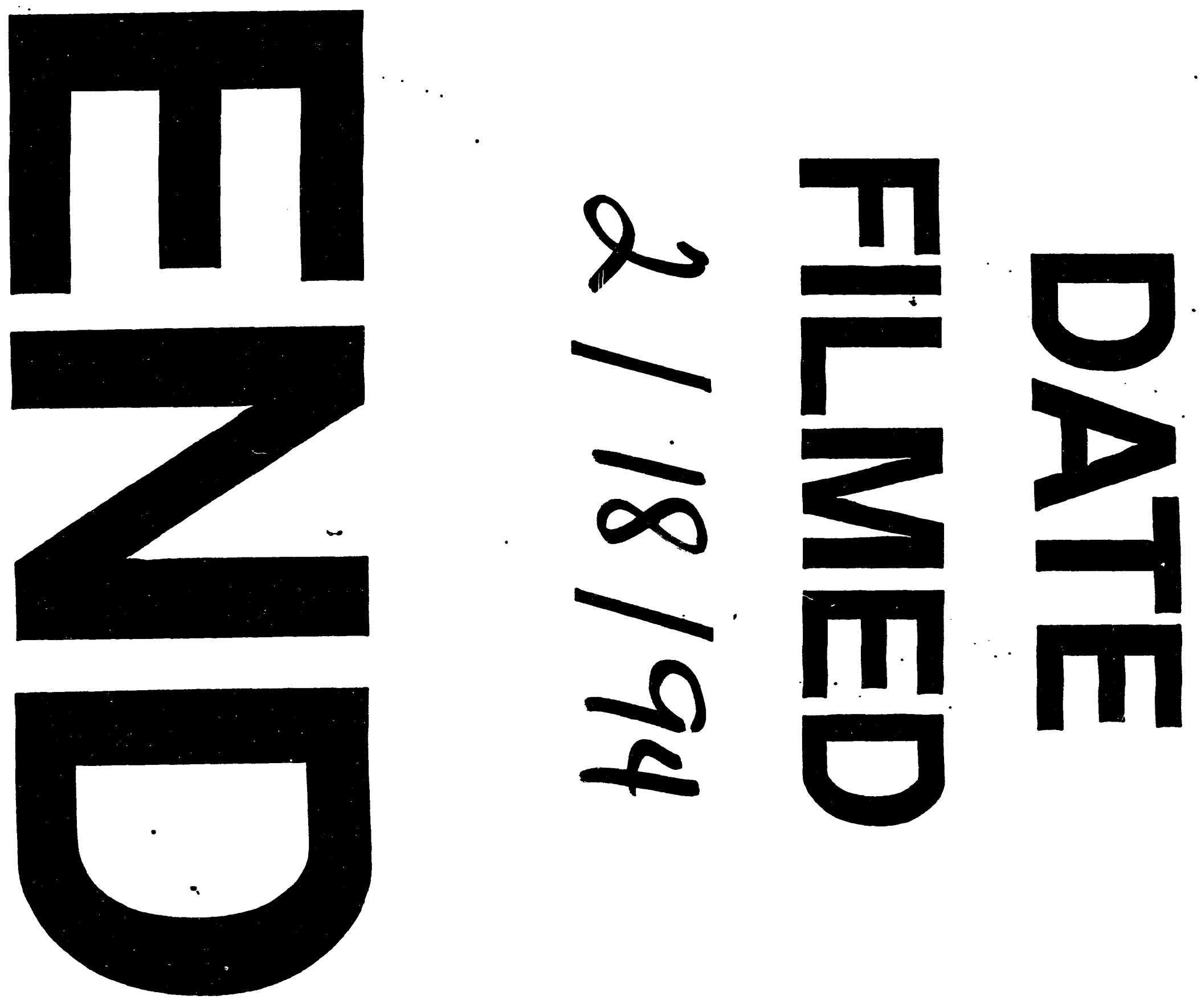
